\title{
Differences in inferred genome-wide signals of positive selection during the evolution of Trypanosoma cruzi and Leishmania spp. lineages: a result of disparities in host and tissue infection ranges?
}

Carlos. A. Flores-López a \& Carlos. A. Machado *

${ }^{a}$ Facultad de Ciencias, Universidad Autónoma de Baja California, Km. 103 Carretera Tijuana - Ensenada, Pedregal Playitas, 22860 Ensenada, Baja California, Mexico

* Department of Biology, University of Maryland, College Park, MD 20742

*Corresponding author: machado@umd.edu

Tel: +1 (301) 405-9447

Short Title: Positive selection in Trypanosoma cruzi and Leishmania spp.

Keywords: Trypanosoma cruzi; Leishmania spp.; positive selection; evolutionary genomics; Chagas disease; Leishmaniasis; vaccine 


\section{ABSTRACT}

Trypanosoma cruzi and Leishmania spp. are kinetoplastids responsible for Chagas disease and Leishmaniasis, neglected tropical diseases for which there are no effective methods of control. These two human pathogens differ widely in the range of mammal species they can infect, their cell/tissue tropism and cell invasion mechanisms. Whether such major biological differences have had any impact on genome-wide patterns of genetic diversification in both pathogens has not been explored. The recent genome sequencing projects of medically important species of Leishmania and T. cruzi lineages provide unique resources for performing comparative evolutionary analyses to address that question. We show that inferred genome-wide signals of positive selection are higher in $T$. cruzi proteins than in Leishmania spp. proteins. We report significant differences in the fraction of protein-coding genes showing evidence of positive selection in the two groups of parasites, and also report that the intensity of positive selection and the proportion of sites under selection are higher in T. cruzi than in Leishmania spp. The pattern is unlikely to be the result of confounding factors like differences in GC content, average gene length or differences in reproductive mode between the two taxa. We propose that the greater versatility of $T$. cruzi in its host range, cell tropism and cell invasion mechanisms may explain the observed differences between the two groups of parasites. Genes showing evidence of positive selection within each taxonomic group may be under diversifying selection to evade the immune system and thus, depending on their functions, could represent viable candidates for the development of drugs or vaccines for these neglected human diseases. 


\section{INTRODUCTION}

Natural selection is the most important evolutionary force driving the diversification of all living organisms. Comparative and population genetic analyses of orthologous DNA sequences are routinely used for inferring the influence of natural selection in shaping levels and patterns of intra and interspecific nucleotide divergence and diversity in natural populations (NIELSEN et al. 2005; OLEKSYK et al. 2010; FAY 2011). In comparative studies of orthologous protein-coding sequences, the action of natural selection during the divergence process is inferred from the value of the ratio of nonsynonymous $(\mathrm{dN})$ to synonymous $(\mathrm{dS})$ substitutions ( $\mathrm{dN} / \mathrm{dS}$ or $\omega$ ). Proteins or sections of proteins under purifying (negative) selection (i.e. selectively constrained) have $d N / d S$ $<1$, while proteins or sections of proteins that have experienced positive selection have $\mathrm{dN} / \mathrm{dS}>1$. However, as usually only a small proportion of codon sites are evolving under positive selection, averaging $\mathrm{dN} / \mathrm{dS}$ over an entire protein is a very conservative approach for inferring natural selection. Consequently, methods that test for codon sites evolving under positive selection are more powerful and accurate (YANG and SWANSON 2002; SWANSON et al. 2003).

Immune system elicitors or antigens from pathogens that evolve rapidly to avoid recognition from the host immune system constitute good examples of protein evolution driven by natural selection (FRANK 2002). With the availability of full genome sequences for multiple pathogen species, bioinformatics and evolutionary analyses focused on the use of $\mathrm{dN} / \mathrm{dS}$ ratios have become powerful approaches for identifying proteins evolving under positive selection that may eventually become candidate genes for parasite control (PeTERSEN et al. 2007; SOYER et al. 2009; Gu et al. 2011; Xu et al. 2011; ZHANG et al. 2011; McCANn et al. 2012).

Chagas disease and Leishmaniasis are neglected tropical diseases for which vaccines are yet to be developed (HOTEZ et al. 2007; BETHONY et al. 2011), making them excellent candidates for conducting in silico searches for protein-coding genes that can be targeted for vaccine or drug development. Trypanosoma cruzi is the etiological agent of Chagas Disease; it infects approximately 8-18 million people, and kills about 20 thousand people every year in Latin America (WHO 2002; RASSI et al. 2010). Leishmaniasis, on the other hand, is caused by more than 20 species of the 
genus Leishmania and has a much wider geographic range, occurring in 88 different countries from Latin America, Asia, Africa and Europe. It is estimated that 12 million people are infected with Leishmania, with approximately 20,000-40,000 deaths per year (DeSJeUX 2001; Alvar et al. 2012).

Trypanosoma cruzi and Leishmania sp. are protozoans that belong to the class Kinetoplastea, an early-diverged branch in the eukaryotic tree of life (SIMPSON et al. 2006). Members of this eukaryotic class have unique characteristics not found in other eukaryotes (SCHMIDT 2005) like polycistronic mRNA modification, uracil insertion modification of mRNA, and the presence of an enlarged mitochondria (i.e. kinetoplast) with a unique chromosomal architecture composed of a few megacircles and thousands of concatenated mini circles. Both parasites have evolved to be digenetic and have independently evolved intracellular evasion mechanisms within their mammal hosts (SIBLEY 2011). Further, both groups of parasites are thought to have originated in South America (YEO et al. 2005; LUKES et al. 2007; ZINGALES et al. 2012), even though they have now different geographic ranges and have adapted to very different insect vectors and mammal hosts. Sylvatic Leishmania has been found mostly in rodents, dogs, foxes and jackals, whereas T. cruzi has a much wider range of mammal hosts (> 100 hosts), including opossums, armadillos, primates, raccoons, rodents, bats, dogs and humans (SCHMIDT 2005; READY 2013). However, one of the most dramatic differences between the two taxa is their contrasting cell/tissue tropism. Leishmania strictly invade macrophages and dendritic cells in the vertebrate host, although short-lived neutrophils are also targeted during the early invasion process (LIU and UZONNA 2012). On the other hand, T. cruzi can invade a much wider array of cell types (e.g. myocytes, macrophages, cardiomyocytes, nerve cells, etc.) (FERNANDES and ANDREWs 2012; MORADIN and DESCOTEAUX 2012), and in fact appears to be able to invade any type of cell in vitro (MANSO-ALVES 2009).

Whether those major differences between T. cruzi and Leishmania spp. in mammal host diversity, cell/tissue tropism and, possibly, cell invasion mechanisms, have had any impact on patterns of genetic diversification genome-wide in both pathogens has yet to be explored. Here we present evolutionary analyses of proteincoding genes from five genomes of $T$. cruzi spp. and four genomes of Leishmania spp.. 
Because $T$. cruzi has a broader host range and can invade a wider array of cell types than Leishmania spp. we hypothesize that $T$. cruzi proteins should show more evidence of adaptive evolution than Leishmania spp. proteins. Genes showing evidence of positive selection within each taxonomic group may be under diversifying selection to evade the immune system and thus, depending on their functions, could represent viable candidates for the development of methods of parasite control.

\section{Materials and methods}

\subsection{Sequence data sets}

We analyzed all available annotated genome sequences from Trypanosoma cruzi and Leishmania spp. available in TriTrypDB release 7.0 (http://tritrypdb.org/tritrypdb/). As of January 2014 four $T$. cruzi genomes as well as the genome of the bat infecting species $T$. cruzi marinkellei, a close relative of $T$. cruzi, had been sequenced and annotated. The four T. cruzi genomes represent 3 of the 6 distinct typing units (DTUs) or lineages (Tcl-TcVI) in which the genetic diversity of $T$. cruzi is currently divided (ZINGALES et al. 2009). They include the most divergent set of lineages of this taxon and thus provide a good representation of genetic divergence within T. cruzi. Because $T$. cruzi has a mainly clonal mode of reproduction (TIBAYRENC et al. 1986; TIBAYRENC and AYALA 1988) T. cruzi DTUs do correspond to genetically isolated entities akin to species. Therefore, despite the difference in taxonomic nomenclature between the two groups we analyze here, the evolutionary divergence among $T$. cruzi DTUs is equivalent to the divergence among Leishmania species, making the comparison appropriate.

Two of the T. cruzi sequenced genomes (haplotypes Esmeraldo (Tcll) and NonEsmeraldo (TcllI)) were obtained during the sequencing of the genome strain of $T$. cruzi CL Brener (EL-SAYED et al. 2005). This strain is a hybrid (MACHADO and AYALA 2001; MACHADO and AYALA 2002; BRISSE et al. 2003), the result of a hybridization event between two divergent lineages that took place $~ 0.4-0.8$ million years ago (FLORESLOPEZ and MACHADO 2011). In our analyses we only use sequences from the parental lineages (Esmeraldo and Non-Esmeraldo) that gave rise to the hybrid (EL-SAYED et al. 2005), therefore avoiding the use of any sequences that could have recombined after 
the hybridization event. We also included two additional genome sequences from lineage Tcl, T. cruzi Sylvio X10/1 (FranzEN et al. 2011) and T. cruzi JRcl4 (unpublished but available in TriTrypDB), as well as the genome of the bat infecting T. cruzi marinkellei strain B7 (FRANZEN et al. 2011). The number of annotated protein coding genes in each sequenced genome is the following: Non-Esmeraldo (10,834), Esmeraldo $(10,342)$, JRcl4 $(7,755)$, Sylvio $(7,456)$ and T. cruzi marinkellei $(10,342)$.

The genetic diversity of Leishmania spp. has been divided into more than 30 species (SCHMIDT 2005). Five Leishmania species associated with humans have had their genomes sequenced: L. major, responsible for cutaneous leishmaniasis $(\mathrm{CL})$ in the old world, L. mexicana and L. braziliensis, both of which cause $C L$ in the new world, and $L$. infantum and $L$. donovani which cause visceral leishmaniasis (VL). Leishmania major (strain Friedlin) was the first Leishmania species sequenced (IVENS et al. 2005), followed by L. infantum and L. braziliensis (PEACOCK et al. 2007). Annotated genome sequences of $L$. mexicana are not published but available in TriTrypDB. The annotated genome sequence of $L$. donovani is available in GeneDB (http://www.genedb.org/). However, this species has very low genetic divergence with $L$. infantum $(\sim 0.48 \%$ average nucleotide divergence) and for that reason it was not included in this study. The number of annotated protein coding genes in each of the 4 Leishmania genomes we included is the following: L. major $(8,408)$, L. infantum $(8,241)$, L. braziliensis $(8,357)$ and L. mexicana $(8,250)$.

\subsection{Ortholog data sets}

Reciprocal best hit blastx searches were conducted to find true orthologs within each taxonomic group. A blastx E-value of $10^{-5}$ was used as threshold for the orthologous search similarity criteria. The approach to identify orthologs using reciprocal best hit blastx searches is conservative due to its low false positive rate and medium false negative rate (CHEN et al. 2007). Within each taxonomic group we conducted reciprocal best-hit blastx searches for all possible pairwise strain comparisons, and selected ortholog pairs that matched across all pairwise comparisons. This conservative approach filtered out almost all proteins that form part of the largest protein families found in T. cruzi (i.e. trans-sialidases, mucins, MASP, surface glycoprotein gp63 
protease) due to large sequence similarities among protein members of these large gene families.

The final datasets of putative orthologs consisted of 3,893 protein-coding genes in Trypanosoma cruzi and 7,439 protein-coding genes in Leishmania spp.. T. cruzi strains were highly dissimilar in terms of the number of predicted protein-coding genes in each genome compared to Leishmania spp.. The CL-Brener haplotypes had an average of 10,588 protein-coding genes per haplotype, similar to the 10,342 genes in T. cruzi marinkellei, while the Tcl strains (Sylvio \& JRcl4) had an average of 7,605 proteincoding genes per strain. The first $T$. cruzi genome sequenced study noted that approximately $50 \%$ of the predicted protein-coding genes were members of few very large protein families (EL-SAYED et al. 2005). The significantly smaller number of protein-coding genes predicted in the Tcl strains is mostly due to differences in the copy number of these large protein families (mostly trans-sialidases, mucins, MASP and gp63s protein families) (FRANZEN et al. 2011). In contrast to T. cruzi, the number of predicted protein-coding genes in the genomes of Leishmania was very similar across species. The largest difference in number of protein-coding genes annotated among Leishmania species was 167 , compared to approximately 3,000 among $T$. cruzi strains. The average Leishmania genome contained 8,314 predicted protein coding-genes, from which an ortholog data set of 7,439 protein coding-genes was constructed.

\subsection{Alignment and selection analyses}

Sequences from each ortholog data set were translated to amino acids with translatorx3.pl (ABASCAL et al. 2010) and aligned with MUSCLE (EDGAR 2004). Aligned data sets were back translated into nucleotides for the selection analyses in PAML (YANG 2007) (see below). Poorly aligned regions were removed using Gblocks (CASTRESANA 2000). Removing poorly aligned regions is a conservative approach that has recently been shown to outweigh the costs of removing true positively selected sites from the analyses (PRIVMAN et al. 2011). Thus, the true number of positively selected sites and/or proteins in our data set might actually be larger than what is presented here. Concatenated data sets of $\sim 1.75$ million base pairs of aligned protein-coding sequence for each group of taxa were used to reconstruct phylogenetic relationships among the $T$. 
cruzi or Leishmania genomes using Maximum likelihood in PhyML (GUINDON et al. 2010) (Figure 1). The DNA substitution models used in the phylogenetic reconstructions were selected for each taxonomic data set using jModeltest (POSADA 2008) (GTR+G for T. cruzi spp. and GTR+I for Leishmania spp.). The phylogenies were then input to PAML for conducting the positive selection analyses independently for each taxonomic dataset using site models that incorporate heterogeneity across sites in the estimates of the $\mathrm{dN} / \mathrm{dS}$ ratio $(\omega)$ and that use phylogenetic information. These tests do not rely on pairwise estimates of $\omega$ and have been shown (DOS REIS and YANG 2013) to be less prone to biases caused by the observed dependency between genetic distance and $\omega$ in pairwise comparisons (ROCHA et al. 2006; Wolf et al. 2009). Pairs of nested models, M7 (beta) versus M8 (beta \& $w$ ) and M8 versus M8a (beta \& $\omega=1$ ), were compared using a likelihood ratio test (LRT). Significance of the LRT for M7 vs M8 was determined using 2 degrees of freedom. Since model M8a is not completely nested within M8, significance was determined by halving the $p$ value from a chi-square test with one degree of freedom as previously suggested (YANG 2007). As we conducted multiple comparisons, the significance of each $p$-value was corrected using the false discovery rate method of Benjamini and Hochberg (BENJAMINI and HOCHBERG 1995) with the p.adjust() function in R. To evaluate the effect of presumed differences in reproductive mode between the two taxa (Leishmania seems to undergo more sexual reproduction than $T$. cruzi), dN/dS values were compared for groups of genes with housekeeping and hypothetical functions to determine if there is evidence of relaxed purifying selection in T. cruzi (See results).

\subsection{Functional overrepresentation analyses}

Functional annotations associated with L. major and the T. cruzi Non-Esmeraldo haplotype were used to determine if any molecular or biological functions were overrepresented among genes showing evidence of positive selection. Unfortunately, between $50 \%$ and $68 \%$ of the protein coding genes in T. cruzi and Leishmania major have unknown functions based on genome annotations, and only 10\% ( 500 proteins) of $T$. cruzi proteins and $42 \%$ (3525 proteins) in L. major have a Gene Ontology term associated to them (www.genedb.org). Consequently, to conduct a more 
comprehensive functional over representation analysis, we additionally clustered all our protein data into Pfam clans (pfam.sanger.ac.uk), a broader classification scheme that groups evolutionary related protein families into clans based on related structure, related function, and significant matching of the same sequence to databases of hidden Markov Models (HMMs) from different families and profile-profile comparisons (FINN et al. 2006). Clustering our data set into Pfam clans allowed us to include many more proteins into the functional overrepresentation analyses. Statistically overrepresented Pfam clans were identified with GeneMerge (CASTILLO-DAVIS and HARTL 2003). All statistical overrepresentation tests were conducted with the protein lists predicted to be under positive selection from the M8 versus M8a model comparison.

\subsection{Hypothetical clustering}

Genes with unknown function (i.e. hypothetical genes) were grouped into protein clusters by conducting a self blastp search $\left(E\right.$ value $\left.<10^{-10}\right)$ of all the hypothetical proteins from the Non-Esmeraldo genome or from the L. major genome. A numerical code (e.g. protein family 1, 2, 3, etc.) was given to all clusters, including proteins from clusters of size 1. GeneMerge was used to determine statistical overrepresentation of protein clusters that had evidence of sites under positive selection (based on the comparison of models M8 and M8a).

\section{RESULTS}

\subsection{More evidence of adaptive evolution in Trypanosoma cruzi than in Leishmania} spp.

Figure 1 shows the phylogenetic relationships among the Leishmania spp. and $T$. cruzi genomes used in this study, reconstructed using maximum likelihood. The overall level of sequence divergence ( $\mathrm{p}$-distance, averaged across orthologous genes) among the $T$. cruzi genomes ranged between 0.015 and 0.086 (Table S1). The overall level of sequence divergence among Leishmania genomes ranged between 0.053 and 0.175 (Table S1). In Leishmania spp. our analyses identified 78 and 170 genes with evidence of positive selection using, respectively, the M8 vs M8a or M7 vs M8 tests of the codon 
site models, representing $1.0 \%$ or $2.3 \%$ of the 7,439 orthologous gene data set from Leishmania (Table 1, p <0.01, Tables S2-S3). In contrast, in T. cruzi, a total of 402 and 451 protein-coding genes presented evidence of positive selection using, respectively, the M8 vs M8a or M7 vs M8 tests of the codon site models, representing $10.33 \%$ or $11.59 \%$ of the 3,893 T. cruzi genes used in this study (Table 1, $\mathrm{p}<0.01$, Tables S4-S5). The number of protein-coding genes showing evidence of positive selection is significantly higher in T. cruzi than in Leishmania spp. (M8 vs M8a: $x^{2}=542.29, p=$ $5.98 \times 10^{-120}$; M7 vs M8: $x^{2}=426.69, p=8.53 \times 10^{-95}$ ) (Table 1, Figure 2). Furthermore, the average $d N / d S$ ratio in sites with $d N / d S>1$ in proteins showing significant evidence of positive selection (Figure 3 ) and the proportion of codon sites under selection in those proteins (Figure 4) are significantly higher in T. cruzi than in Leishmania spp (Wilcoxon rank-sum test, $\mathrm{p}<0.0001$ ).

To examine the effect of removing highly divergent codons from the alignment we performed the $T$. cruzi ortholog alignments without alignment edition by Gblocks (CASTRESANA 2000), which removes highly divergent aligned regions. It is important to note that recent analyses (PRIVMAN et al. 2011) show that the benefits of using aligner filters in studies of this nature outweigh the costs of removing true positively selected sites from the analyses. Without the Gblocks alignment edition, the number of genes predicted to be under positive selection in T. cruzi spp. increases from 776 to 954 using the M7 vs M8 model comparison and from 714 to 892 using the M8 vs M8a comparison, confirming that our reported results are conservative. Similar results were observed in Leishmania spp., and thus the number of proteins predicted to be under positive selection in T. cruzi remained larger than those predicted in Leishmania spp (not shown).

Low divergence at synonymous sites (dS) could generate false positives with high dN/dS particularly in pairwise sequence comparisons (RocHA et al. 2006; Wolf et al. 2009; Dos REIS and YANG 2013). However, T. cruzi proteins under positive selection had a significantly higher divergence at synonymous sites compared to proteins under purifying selection (Wilcoxon rank-sum test, $\mathrm{p}=0.0144$ ), whereas the Leishmania spp. proteins under positive selection did not show any significant difference with those under purifying selection ( $p=0.38$ ). Furthermore, the distribution of $d N / d S$ values for all 
proteins when comparing the most divergent lineages of Leishmania spp. ( $L$. braziliensis vs L. mexicana) or T. cruzi (T. cruzi Sylvio strain vs $T$. cruzi marinkellel) is still significantly different between the two taxa (Wilcoxon rank-sum text, $p<0.0001$ ) (Figure 5). Therefore, it is unlikely that the results we report are caused by artifacts generated by low divergence at synonymous sites in the $T$. cruzi dataset.

Differences in GC content do not affect the performance of the codon models used (ZHAl et al. 2012), and we saw no difference in GC content of genes with different evidence of selection (Table S7). The only sequence characteristic that has been shown to have an effect on the performance of the codon models used is gene length (ZHAl et al. 2012), as there is more power to detect selection in longer genes (ANISIMOVA et al. 2001). We in fact observed the same trend of significantly longer gene length in the set of positive selected genes and those under purifying selection both in T. cruzi (M7 vs M8: 2158 vs 1599, $\mathrm{p}<0.001$; M8 vs M8a: 2195 vs 1603, $\mathrm{p}<0.001$ ) and Leishmania spp. (M7 vs M8: 2280 vs 1998, $p=0.015$; M8 vs M8a: 2458 vs 1999, $p=0.024$ ) (Table S7). However, the protein coding genes in the Leishmania spp. data set were significantly longer than those of $T$. cruzi spp. $\left(p=9.34 \times 10^{-13}\right)$. Given that more selection was detected in the dataset with the shorter gene length, it is unlikely that this factor has influenced the overall results.

Differences in reproductive mode (asexual vs sexual) can be problematic for interpreting differences in patterns of adaptive evolution. Theory suggests that asexual lineages should undergo a relaxation of purifying selection with the consequence of an overall increase of $\mathrm{Ka} / \mathrm{Ks}$ ratios relative to sexually reproducing lineages due to the faster accumulation of deleterious mutations expected in smaller populations (CHARLESWORTH and WRIGHT 2001; GLEMIN 2007), although empirical results have not always been consistent with that prediction (PALAND and LYNCH 2006; BARRACLOUGH et al. 2007; HeNRY et al. 2012; OLLIVIER et al. 2012). It is widely accepted that $T$. cruzi reproduces mostly asexually (TIBAYRENC et al. 1986; TIBAYRENC and AYALA 2002) although there is strong evidence that rare sexual recombination events have occurred (MACHADO and AYALA 2001; BrISSE et al. 2003; FLORES-LOPEZ and MACHADO 2011), a finding consistent with the observed capacity of this parasite to undergo genetic exchange in the lab (GAUNT et al. 2003). Although there has been more controversy 
about the reproductive mode of Leishmania species (TIBAYRENC and AYALA 2013), recent studies on L. donovani/infantum (ROGERS et al. 2014), L. major (AKOPYANTS et al. 2009; INBAR et al. 2013) and L. braziliensis (ROUGERON et al. 2009) suggest that Leishmania alternate clonal propagation with sexual reproduction. Given that Leishmania seems to undergo more sexual reproduction than T. cruzi (acknowledging that we have no information for $T$. cruzi marinkellel) we hypothesize that if our reported results are due to reduced levels of genome-wide purifying selection rather than increased adaptive evolution in $T$. cruzi we should observe evidence of relaxed purifying selection in housekeeping genes in this taxon. For each taxon we compared dN/dS values from 47 genes that had the same housekeeping functions in both taxa (e.g. DNA and RNA polymerases, Ribosomal proteins, histones, cytochromes, kinases, helicases) with $\mathrm{dN} / \mathrm{dS}$ values of approximately 300 genes encoding hypothetical proteins (Table S6). The latter set of genes are expected to have lower selective constraints than housekeeping genes and were chosen at random from the large suite of annotated hypothetical genes from each taxon. The $\mathrm{dN} / \mathrm{dS}$ values of housekeeping genes were significantly lower than hypothetical genes for both $T$. cruzi spp. $\left(p=3.07 \times 10^{-25}\right.$; housekeeping genes mean $\mathrm{dN} / \mathrm{dS}=0.223$, hypothetical genes mean $\mathrm{dN} / \mathrm{dS}=0.748$ ) and Leishmania spp. $\left(p=8.5 \times 10^{-15}\right.$; housekeeping genes mean $\mathrm{dN} / \mathrm{dS}=0.167$, hypothetical genes mean $\mathrm{dN} / \mathrm{dS}=0.387$ ) (Figure 6 ). The difference in mean $\mathrm{dN} / \mathrm{dS}$ values between housekeeping and hypothetical genes is thus much greater in $T$. cruzi spp. than in Leishmania spp. suggesting that purifying selection is still playing a very important role in $T$. cruzi protein evolution. That conclusion is reinforced by the additional observation that while the difference between both taxa in $\mathrm{dN} / \mathrm{dS}$ values for housekeeping genes is barely significant $(p=0.03)$ it is highly significant for hypothetical genes $\left(p=1.78 \times 10^{-57}\right)$. The results are also consistent with a previous detailed population genetic study that also found evidence of purifying selection in two housekeeping genes of T.cruzi (MACHADO and AYALA 2002).

\subsection{Functional overrepresentation of genes under positive selection.}

In Leishmania spp., 4 functional categories were statistically overrepresented in 
the genes showing evidence of positive selection $(p<0.01)$ (Table 2). The most significant was glutathione peroxidase, followed by ATP binding cassette, iron superoxide dismutase and cysteine peptidase. Interestingly, proteins with those functions have been shown to play some role in the evolution of drug resistance (ATP binding cassette) (PURKAIT et al. 2012), in the interaction with the host immune system (Cysteine peptidase) (MotTram et al. 2004; AleXANDER and Bryson 2005), or have been proposed as vaccine candidates for Leishmaniasis (iron superoxidase dismutase) (DAIFALLA et al. 2012) (see Discussion).

In Trypanosoma cruzi, there were only 2 over represented functions among those showing evidence of positive selection ( $p<0.01)$ : genes with hypothetical functions (discussed below) and genes with mucin function (Table 2). The latter is an important finding given the important role played by mucins in protecting the parasite from both vector and mammal host defense mechanisms and their role in guaranteeing an anchorage point during the parasite invasion process (BUSCAGLIA et al. 2006; DE PABLOS and OSUNA 2012).

\subsection{Hypothetical genes under positive selection.}

Although the ortholog dataset of $T$. cruzi had a smaller number of hypothetical proteins than Leishmania spp. (2796 vs 5054), a significantly higher proportion of hypothetical proteins were predicted to be under positive selection in T. cruzi (M8 vs M8a: 572 vs $140, x^{2}=547.07, p=5.46 \times 10^{-121}$; M7 vs M8: 585 vs $242, x^{2}=388.02$, $\left.\mathrm{p}=2.23 \times 10^{-86}\right)$. In an attempt to increase the power of the analysis of proteins with unknown function, all those proteins were clustered based on sequence similarity. Of the 2796 hypothetical proteins within the $T$. cruzi ortholog data set, 461 clusters were formed after the sequence similarity cluster criteria $\left(\mathrm{E}\right.$ value $\left.<10^{-10}\right)$. In the Leishmania spp. ortholog data set 830 clusters were formed. These results show, as expected, that most hypothetical proteins are not part of large protein families, reducing the power of functional overrepresentation analyses. Of the clusters of hypothetical proteins recovered, only 3 clusters in $T$. cruzi and 2 clusters in Leishmania spp. were overrepresented among those under positive selection (Table 3). 


\section{DISCUSSION}

We show that we can infer more evidence of positive selection in $T$. cruzi proteins than in Leishmania spp. proteins. Because T. cruzi has a mainly clonal mode of reproduction (TIBAYRENC et al. 1986; TIBAYRENC and AYALA 1988) T. cruzi DTUs do correspond to genetically isolated entities akin to species. Thus, the evolutionary divergence among $T$. cruzi DTUs is equivalent to the divergence among Leishmania species, making the comparison appropriate. First, we report that a significantly larger fraction of protein-coding genes show evidence of positive selection in Trypanosoma cruzi than in Leishmania spp (Table 1, Figure 2). Furthermore, we report that the average $\mathrm{dN} / \mathrm{dS}$ of sites under positive selection and the proportion of sites under positive selection in genes showing a signal of positive selection are significantly higher in $T$. cruzi than in Leishmania spp. (Figure 3 ). What makes our results more startling is the fact that the majority of surface protein families of $T$. cruzi, which make up almost $50 \%$ of the genes in its genome were unavoidably filtered out of our gene data set due to the strict orthologous gene criteria that was used. Given the immune related function of those protein families our results are indicative that the number of proteins that have been under positive selection in $T$. cruzi should be larger than the number reported here.

The reported results are not artifacts of the analyses. Removing or not removing highly divergent regions using GBlocks does not affect the overall results. Further, low levels of sequence divergence at silent sites have not influenced the inference of adaptive evolution. Although the overall level of divergence was smaller among $T$. cruzi strains ( $p$-distance: 0.015-0.086) than among Leishmania species ( $p$-distance: 0.053 $0.175)$, a similar comparative genomic study in primates observed the opposite trend that we report: significantly smaller number of proteins were predicted to be under positive selection with the less divergent sample of primate species (GEORGE et al. 2011). Moreover, we show that the pattern is not the result of possible differences in reproductive mode between the two taxa, or differences in GC content or gene length.

We propose that the larger number of hosts mammal species, the larger number of target cells and tissues it can infect, and the more diverse intracellular invasive developmental stages of Trypanosoma cruzi are the underlying reasons behind the 
observed difference in the number of proteins inferred to have experienced adaptive evolution in the two taxa. Those major differences in the biology of the two groups of parasites should influence the level of interaction between the parasite, surface receptors of host target cells and/or the immune system of their different hosts, and can therefore influence patterns of protein evolution in immune elicitors of the parasite and in proteins involved in cell invasion. Species from the genus Leishmania are known to almost exclusively depend on macrophages and dendritic cells for their intracellular survival mechanism (LIU and UZONNA 2012) within their relatively small number of mammal hosts (SCHMIDT 2005; READY 2013). Although there are some lizard-infecting species of Leishmania that live in the lumen of the cloacae, the intestine or in the bloodstream of lizards and do not infect macrophages, none of these species were included in this study and there has been a debate among taxonomists about the placement of these species within the genus Leishmania or the subgenus Sauroleishmania (NOYES et al. 1998). On the other hand T. cruzi has the ability to invade any type of cell in humans during the initial phases of infection, even though the parasite does tend to have tropism towards muscle and nerve cells (SCHMIDT 2005). The pathology of $T$. cruzi in its estimated 180 mammal reservoir species is not well known (WHO 2002; NoIREAU et al. 2009). It is unlikely that the capacity to invade multiple cell types is a characteristic unique to the interaction between T. cruzi and humans given the recent age of this interaction and the vast number and diversity of mammal species $T$. cruzi is known to infect. The wider range of host cells and host species that $T$. cruzi can infect, combined with its more complex life cycle, exposes the parasite to more diverse intra- and extracellular environments and has thus exposed a larger number of its proteins to selective pressures during its evolution compared to Leishmania. Proteins directly exposed to the immune system as well as proteins that directly interact with surface receptors of the wide range of cell types $T$. cruzican invade should have been exposed to different levels of selection. Therefore, we hypothesize that the higher versatility of $T$. cruzi is the most likely reason for the significant differences in the fraction of proteins under positive selection (Figure 2) and the more intense levels of selection in those proteins between the two taxa (Figure 3). We stress the fact that selection pressures have been exerted mostly by non-human hosts of 
these parasites given the short time of association of these parasites with humans.

The availability of annotated genome sequences from human pathogens has made feasible the application of in silico methods to identify proteins with immunogenic properties that could become candidates for parasite control. Recent studies have provided solid evidence that candidates for vaccine development can be identified by surveying parasite's genomes for proteins in which few amino acid sites have experienced high rates of amino acid substitution (consistent with the action of positive selection) while the rest of the protein is under strong purifying selection (SUZUKI 2004; Gu et al. 2011; McCANn et al. 2012). The rationale behind this idea is that proteins with those characteristics have regions that are rapidly evolving because of their recognition by the host's immune system, but also have conserved regions under strong negative selection that may have a critical role in the biology of the pathogen. Effective vaccines or drugs with long-term effectiveness would target those conserved regions rather than the rapidly changing regions of those proteins (BURTON et al. 2012), although there is some evidence that polymorphic regions under balancing selection can also be very effective immune elicitors (OSIER et al. 2007; WEEDALL and CONWAY 2010).

Our study is the first to use comparative evolutionary analyses for generating a preliminary list of potentially useful immunogenic proteins in Leishmaniasis and Chagas disease (Tables S2-S5). In Leishmania spp. the most interesting overrepresented function with genes under positive selection was iron superoxidase dismutase, since one gene from this protein family was recently proposed as a vaccine candidate for Leishmaniasis due to the protective role it induced in mice (DAIFALLA et al. 2012). That result further reinforces the point that evolutionary approaches can play a major role in detecting immunogenic molecules. In addition, we found four additional overrepresented functions, some of which have been shown to play some role in the evolution of drug resistance (ATP binding cassette) or in the interaction with the host immune system (Cysteine peptidase). ATP binding cassette was the second most significant overrepresented function. Members of this large protein family are known to be involved in the development of amphotericin-B drug resistance in L. donovani (PURKAIT et al. 2012). This antifungal compound (amphotericin-B) is the main drug therapy employed by the WHO to treat visceral leishmaniasis. It would be of particular interest to 
determine if the sites predicted to be under positive selection in these proteins are directly involved in the development of amphotericin-B drug resistance. Further, Cysteine peptidases are known to play a very important role in the manipulation of the host's immune response in $L$. mexicana by controlling the T-helper cell response, which has been shown to determine the fate of the infection (MOTTRAM et al. 2004; AlEXANDER and BRYSON 2005). Interestingly the phylogenetic branches leading to $L$. mexicana in both ortholog data sets appear to be under positive selection (data not shown).

In Trypanosoma cruzi we found that Mucin proteins were overrepresented among those showing signals of positive selection. However, while the heavy glycosylation and hypervariability of Mucin proteins does not favor their consideration as logical drug/vaccine candidates for $T$. cruzi, other characteristics like their cell membrane location and role in the mechanisms of intracellular invasion (BUSCAGLIA et al. 2006) suggests the contrary. Unfortunately there are still many proteins of this parasite with unknown function, and our analyses suggest that many of these unknown proteins have experienced adaptive evolution. However, without a biological function associated to these proteins and without knowing whether they are cell surface proteins it is difficult to evaluate their utility in methods of parasite control.

In summary, we show that natural selection has played a larger role in the evolution of $T$. cruzi proteins than in the evolution of Leishmania spp. proteins. We propose that this difference is the result of the greater versatility of $T$. cruzi in terms of mammal species it can infect, its cell tropism and its intracellular invasion mechanisms. We provide a list of proteins that have evolved under positive selection that could be evaluated in methods of parasite control in both human diseases. Identification of a protein that was recently proposed as a Leishmaniasis vaccine using our evolutionary analyses confirms the importance that comparative evolutionary studies can have on the exploration of vaccine candidates.

\section{ACKNOWLEDGMENTS}

We thank Maximilian J. Telford for help on the translation/alignment analyses, and Kawther Abdilleh, Kevin Nyberg, Guilherme Targino Valente and two anonymous 
reviewers for constructive suggestions. Work partially supported by University of Maryland startup funds and by NSF award MCB-1026200 to CAM.

\section{AUTHOR CONTRIBUTIONS}

Conceived and designed the experiments: CAF-L CAM. Performed the experiments:

CF-L. Analyzed the data: CF-L CAM. Contributed reagents/

materials/analysis tools: CAM. Wrote the paper: CF-L CAM. 


\section{REFERENCES}

ABASCAL, F., R. ZARDOYA and M. J. TELFORD, 2010 TranslatorX: multiple alignment of nucleotide sequences guided by amino acid translations. Nucleic Acids Res 38: W7-13.

Akopyants, N. S., N. Kimblin, N. Secundino, R. Patrick, N. Peters et al., 2009 Demonstration of genetic exchange during cyclical development of Leishmania in the sand fly vector. Science 324: 265-268.

AleXANDER, J., and K. BRYSON, 2005 T helper (h)1/Th2 and Leishmania: paradox rather than paradigm. Immunology letters 99: 17-23.

Alvar, J., I. D. Velez, C. Bern, M. Herrero, P. Desjeux et al., 2012 Leishmaniasis worldwide and global estimates of its incidence. PLoS One 7: e35671.

ANISIMOVA, M., J. P. BIELAWSKI and Z. YANG, 2001 Accuracy and power of the likelihood ratio test in detecting adaptive molecular evolution. Mol Biol Evol 18: 1585-1592.

BarRaclough, T. G., D. Fontaneto, C. RICCI and E. A. Herniou, 2007 Evidence for inefficient selection against deleterious mutations in cytochrome oxidase I of asexual bdelloid rotifers. Mol Biol Evol 24: 1952-1962.

BenJAminI, Y., and Y. HochBERG, 1995 Controlling the False Discovery Rate - a Practical and Powerful Approach to Multiple Testing. Journal of the Royal Statistical Society Series B-Methodological 57: 289-300.

Bethony, J. M., R. N. Cole, X. Guo, S. KamhaWI, M. W. Lightowlers et al., 2011 Vaccines to combat the neglected tropical diseases. Immunol Rev 239: 237-270.

Brisse, S., J. Henriksson, C. BARnABe, E. J. Douzery, D. BerkVEens et al., 2003 Evidence for genetic exchange and hybridization in Trypanosoma cruzi based on nucleotide sequences and molecular karyotype. Infection, genetics and evolution : journal of molecular epidemiology and evolutionary genetics in infectious diseases 2: 173-183.

Burton, D. R., P. POIGNARD, R. L. StANFieLd and I. A. WILSON, 2012 Broadly neutralizing antibodies present new prospects to counter highly antigenically diverse viruses. Science 337: 183-186.

Buscaglia, C. A., V. A. Campo, A. C. Frasch and J. M. Di Nola, 2006 Trypanosoma cruzi surface mucins: host-dependent coat diversity. Nature reviews. Microbiology 4: 229-236.

CASTILLO-DAVIS, C. I., and D. L. HARTL, 2003 GeneMerge--post-genomic analysis, data mining, and hypothesis testing. Bioinformatics 19: 891-892.

CASTRESANA, J., 2000 Selection of conserved blocks from multiple alignments for their use in phylogenetic analysis. Mol Biol Evol 17: 540-552.

ChARLESWORTH, D., and S. I. WRIGHT, 2001 Breeding systems and genome evolution. Curr Opin Genet Dev 11: 685-690.

CHEN, F., A. J. MACKEY, J. K. VeRMUNT and D. S. Roos, 2007 Assessing performance of orthology detection strategies applied to eukaryotic genomes. PLoS One 2: e383.

DaIFALLA, N. S., A. G. BAYIH and L. GedAMU, 2012 Leishmania donovani recombinant iron superoxide dismutase $B 1$ protein in the presence of TLR-based adjuvants induces partial protection of BALB/c mice against Leishmania major infection. Experimental parasitology.

De Pablos, L. M., and A. OsunA, 2012 Multigene families in Trypanosoma cruzi and their role in infectivity. Infection and immunity 80: 2258-2264. 
DESJEUX, P., 2001 The increase in risk factors for leishmaniasis worldwide. Transactions of the Royal Society of Tropical Medicine and Hygiene 95: 239-243.

Dos REIS, M., and Z. YANG, 2013 Why do more divergent sequences produce smaller nonsynonymous/synonymous rate ratios in pairwise sequence comparisons? Genetics 195: 195-204.

EDGAR, R. C., 2004 MUSCLE: multiple sequence alignment with high accuracy and high throughput. Nucleic Acids Res 32: 1792-1797.

El-Sayed, N. M., P. J. Myler, D. C. Bartholomeu, D. Nilsson, G. Aggarwal et al., 2005 The genome sequence of Trypanosoma cruzi, etiologic agent of Chagas disease. Science 309: 409-415.

FAY, J. C., 2011 Weighing the evidence for adaptation at the molecular level. Trends in genetics : TIG 27: 343-349.

FERNANDES, M. C., and N. W. ANDREWS, 2012 Host cell invasion by Trypanosoma cruzi: a unique strategy that promotes persistence. FEMS microbiology reviews 36 : 734-747.

FinN, R. D., J. Mistry, B. SChUster-BockleR, S. GRifFiths-JONES, V. HOllich et al., 2006 Pfam: clans, web tools and services. Nucleic Acids Res 34: D247-251.

Flores-LoPEZ, C. A., and C. A. MACHADO, 2011 Analyses of 32 loci clarify phylogenetic relationships among Trypanosoma cruzi lineages and support a single hybridization prior to human contact. PLoS Negl Trop Dis 5: e1272.

Frank, S. A., 2002 Immunology and evolution of infectious disease. Princeton University Press, Princeton,.

Franzen, O., S. Ochaya, E. Sherwood, M. D. LeWIS, M. S. LleWellyn et al., 2011 Shotgun sequencing analysis of Trypanosoma cruzi I Sylvio X10/1 and comparison with T. cruzi VI CL Brener. PLoS Negl Trop Dis 5: e984.

Gaunt, M. W., M. Yeo, I. A. Frame, J. R. Stothard, H. J. Carrasco et al., 2003 Mechanism of genetic exchange in American trypanosomes. Nature 421: 936939.

George, R. D., G. McVickeR, R. Diederich, S. B. NG, A. P. MAcKenzie et al., 2011 Trans genomic capture and sequencing of primate exomes reveals new targets of positive selection. Genome research 21: 1686-1694.

GLEMIN, S., 2007 Mating systems and the efficacy of selection at the molecular level. Genetics 177: 905-916.

GU, M., W. LIU, L. XU, Y. CAO, C. YAO et al., 2011 Positive selection in the hemagglutinin-neuraminidase gene of Newcastle disease virus and its effect on vaccine efficacy. Virology journal 8: 150.

Guindon, S., J. F. Dufayard, V. Lefort, M. Anisimova, W. HordiJK et al., 2010 New algorithms and methods to estimate maximum-likelihood phylogenies: assessing the performance of PhyML 3.0. Systematic biology 59: 307-321.

HenRY, L., T. SchWANDER and B. J. CRESPI, 2012 Deleterious mutation accumulation in asexual Timema stick insects. Mol Biol Evol 29: 401-408.

Hotez, P. J., D. H. MolyneuX, A. Fenwick, J. Kumaresan, S. E. Sachs et al., 2007 Control of neglected tropical diseases. The New England journal of medicine 357: 1018-1027. 
InBar, E., N. S. Akopyants, M. Charmoy, A. Romano, P. LAWYER et al., 2013 The mating competence of geographically diverse Leishmania major strains in their natural and unnatural sand fly vectors. PLoS Genet 9: e1003672.

Ivens, A. C., C. S. Peacock, E. A. Worthey, L. Murphy, G. AggarWal et al., 2005 The genome of the kinetoplastid parasite, Leishmania major. Science 309: 436-442.

LIU, D., and J. E. UZONNA, 2012 The early interaction of Leishmania with macrophages and dendritic cells and its influence on the host immune response. Front Cell Infect Microbiol 2: 83.

LUKES, J., I. L. MAURICIO, G. SCHONIAN, J. C. DuJARDIN, K. Soteriadou et al., 2007 Evolutionary and geographical history of the Leishmania donovani complex with a revision of current taxonomy. Proc Natl Acad Sci U S A 104: 9375-9380.

MACHADO, C. A., and F. J. AYALA, 2001 Nucleotide sequences provide evidence of genetic exchange among distantly related lineages of Trypanosoma cruzi. Proc Natl Acad Sci U S A 98: 7396-7401.

MACHADO, C. A., and F. J. AYALA, 2002 Sequence variation in the dihydrofolate reductase-thymidylate synthase (DHFR-TS) and trypanothione reductase (TR) genes of Trypanosoma cruzi. Mol Biochem Parasitol 121: 33-47.

MANSO-ALVES, M. J. A.-M., R., 2009 A century of research: what have we learned about the interactions of Trypanosoma cruzi with host cells? Mem. Inst. Osw. Cruzi 104: 76-88.

McCann, H. C., H. NAHAL, S. ThakUR and D. S. Guttman, 2012 Identification of innate immunity elicitors using molecular signatures of natural selection. Proc Natl Acad Sci U S A 109: 4215-4220.

Moradin, N., and A. DescoteAuX, 2012 Leishmania promastigotes: building a safe niche within macrophages. Frontiers in cellular and infection microbiology 2: 121.

Mottram, J. C., G. H. CoomBs and J. AleXANDER, 2004 Cysteine peptidases as virulence factors of Leishmania. Current opinion in microbiology 7: 375-381.

Nielsen, R., C. Bustamante, A. G. Clark, S. Glanowski, T. B. Sackton et al., 2005 A scan for positively selected genes in the genomes of humans and chimpanzees. PLoS biology 3: e170.

NoIREAU, F., P. Diosque and A. M. JANSEN, 2009 Trypanosoma cruzi: adaptation to its vectors and its hosts. Veterinary research 40: 26.

Noyes, H. A., M. L. ChANCE, D. G. Croan and J. T. ElLIS, 1998 Leishmania (sauroleishmania): a comment on classification. Parasitology today 14: 167.

OLEKSYK, T. K., M. W. SMITH and S. J. O'BRIEN, 2010 Genome-wide scans for footprints of natural selection. Philosophical transactions of the Royal Society of London. Series B, Biological sciences 365: 185-205.

Ollivier, M., T. Gabaldon, J. Poulain, F. Gavory, N. Leterme et al., 2012 Comparison of gene repertoires and patterns of evolutionary rates in eight aphid species that differ by reproductive mode. Genome Biol Evol 4: 155-167.

Osier, F. H., S. D. Polley, T. Mwangl, B. Lowe, D. J. Conway et al., 2007 Naturally acquired antibodies to polymorphic and conserved epitopes of Plasmodium falciparum merozoite surface protein 3. Parasite Immunol 29: 387-394.

PALAND, S., and M. LYNCH, 2006 Transitions to asexuality result in excess amino acid substitutions. Science 311: 990-992. 
Peacock, C. S., K. Seeger, D. Harris, L. Murphy, J. C. Ruiz et al., 2007 Comparative genomic analysis of three Leishmania species that cause diverse human disease. Nature genetics 39: 839-847.

Petersen, L., J. P. Bollback, M. Dimmic, M. Hubisz and R. Nielsen, 2007 Genes under positive selection in Escherichia coli. Genome Res 17: 1336-1343.

POSADA, D., 2008 jModelTest: phylogenetic model averaging. Mol Biol Evol 25: 12531256.

Privman, E., O. Penn and T. PuPKo, 2011 Improving the performance of positive selection inference by filtering unreliable alignment regions. Mol Biol Evol 29: 1-5.

Purkait, B., A. Kumar, N. NANDI, A. H. SARDAR, S. Das et al., 2012 Mechanism of amphotericin $B$ resistance in clinical isolates of Leishmania donovani. Antimicrobial agents and chemotherapy 56: 1031-1041.

RASSI, A., JR., A. RASSI and J. A. MARIN-NETO, 2010 Chagas disease. Lancet 375: 13881402.

REAdY, P. D., 2013 Biology of Phlebotomine Sand Flies as Vectors of Disease Agents. Annual Review of Entomology, Vol 58 58: 227-250.

Rocha, E. P., J. M. SMith, L. D. HuRSt, M. T. Holden, J. E. CoOper et al., 2006 Comparisons of $\mathrm{dN} / \mathrm{dS}$ are time dependent for closely related bacterial genomes. J Theor Biol 239: 226-235.

Rogers, M. B., T. Downing, B. A. Smith, H. IMAMURA, M. SANDERS et al., 2014 Genomic confirmation of hybridisation and recent inbreeding in a vector-isolated Leishmania population. PLoS Genet 10: e1004092.

Rougeron, V., T. De Meeus, M. Hide, E. WaleckX, H. Bermudez et al., 2009 Extreme inbreeding in Leishmania braziliensis. Proc Natl Acad Sci U S A 106: 1022410229.

SCHMIDT, G. D. R., L.S., 2005 Foundations of Parasitology.

SIBLEY, L. D., 2011 Invasion and intracellular survival by protozoan parasites. Immunological reviews 240: 72-91.

SIMPSON, A. G., Y. INAGAKI and A. J. ROGER, 2006 Comprehensive multigene phylogenies of excavate protists reveal the evolutionary positions of "primitive" eukaryotes. Molecular biology and evolution 23: 615-625.

Soyer, Y., R. H. OrSi, L. D. Rodriguez-RIVERA, Q. Sun and M. WiedmanN, 2009 Genome wide evolutionary analyses reveal serotype specific patterns of positive selection in selected Salmonella serotypes. BMC Evol Biol 9: 264.

SUZUKI, Y., 2004 Negative selection on neutralization epitopes of poliovirus surface proteins: implications for prediction of candidate epitopes for immunization. Gene 328: 127-133.

Swanson, W. J., R. Nielsen and Q. YANG, 2003 Pervasive adaptive evolution in mammalian fertilization proteins. Mol Biol Evol 20: 18-20.

TIBAYRENC, M., and F. J. AYALA, 1988 Isozyme variability in Trypanosoma cruzi, the agent of Chagas' disease: Genetical, taxonomical, and epidemiological significance. Evolution 42: 277-292.

TiBAYRENC, M., and F. J. AYALA, 2002 The clonal theory of parasitic protozoa: 12 years on. Trends in parasitology 18: 405-410.

TIBAYRENC, M., and F. J. AYALA, 2013 How clonal are Trypanosoma and Leishmania? Trends Parasitol 29: 264-269. 
Tibayrenc, M., P. WARD, A. MoYA and F. J. Ayala, 1986 Natural populations of Trypanosoma cruzi, the agent of Chagas disease, have a complex multiclonal structure. Proceedings of the National Academy of Sciences of the United States of America 83: 115-119.

WeEdALL, G. D., and D. J. ConWAY, 2010 Detecting signatures of balancing selection to identify targets of anti-parasite immunity. Trends Parasitol 26: 363-369.

WHO, 2002 Control of Chagas disease. World Health Organ Tech Rep Ser 905: i-vi, 1109, back cover.

Wolf, J. B., A. Kunstner, K. NAm, M. Jakobsson and H. Ellegren, 2009 Nonlinear dynamics of nonsynonymous (dN) and synonymous (dS) substitution rates affects inference of selection. Genome Biol Evol 1: 308-319.

XU, Z., H. CHEN and R. ZHOU, 2011 Genome-wide evidence for positive selection and recombination in Actinobacillus pleuropneumoniae. BMC Evol Biol 11: 203.

YANG, Z., 2007 PAML 4: phylogenetic analysis by maximum likelihood. Mol Biol Evol 24: 1586-1591.

YANG, Z., and W. J. SWANSON, 2002 Codon-substitution models to detect adaptive evolution that account for heterogeneous selective pressures among site classes. Mol Biol Evol 19: 49-57.

Yeo, M., N. Acosta, M. Llewellyn, H. Sanchez, S. Adamson et al., 2005 Origins of Chagas disease: Didelphis species are natural hosts of Trypanosoma cruzi I and armadillos hosts of Trypanosoma cruzi II, including hybrids. Int J Parasitol 35: 225-233.

ZHAI, W., R. NiELSEN, N. GoldMAN and Z. YANG, 2012 Looking for Darwin in genomic sequences--validity and success of statistical methods. Mol Biol Evol 29: 28892893.

ZHANG, Y., H. ZHANG, T. ZHOU, Y. ZHONG and Q. JIN, 2011 Genes under positive selection in Mycobacterium tuberculosis. Comput Biol Chem 35: 319-322.

Zingales, B., S. G. Andrade, M. R. Briones, D. A. CAmpbell, E. Chiari et al., 2009 A new consensus for Trypanosoma cruzi intraspecific nomenclature: second revision meeting recommends Tcl to TcVI. Mem Inst Oswaldo Cruz 104: 10511054.

Zingales, B., M. A. Miles, D. A. Campbell, M. Tibayrenc, A. M. Macedo et al., 2012 The revised Trypanosoma cruzi subspecific nomenclature: rationale, epidemiological relevance and research applications. Infect Genet Evol 12: 240-253. 


\section{FIGURE LEGENDS}

Figure 1. Phylogenetic relationships of the Leishmania sp. or Trypanosoma cruzi genomes used in this study. The unrooted maximum likelihood phylogenies used in the PAML analyses are shown for A) Leishmania spp. B) T. cruzi. In each case, the phylogeny was reconstructed using a concatenated data set of 1.75 million base pairs of aligned coding sequence. The GTR substitution model was used in both analyses.

Figure 2. Difference in the number of proteins showing evidence of positive selection within each taxa. A) Data for codon models M7 versus M8 $(p<0.01)$. B) Data for codon models M8 versus M8a $(p<0.01)$. The observed difference is highly significant (M8 vs M8a: $x^{2}=693.33, p=8.43 \times 10^{-153} ;$ M7 vs M8: $x^{2}=503.86, p=1.37 \times 10^{-111}$ ).

Figure 3. $\mathrm{dN} / \mathrm{dS}$ for sites predicted to be evolving under positive selection. Boxplot of $\mathrm{dN} / \mathrm{dS}$ values in sites evolving under positive selection in all the proteins showing evidence of adaptive evolution using the M8 vs M8a model tests $(p<0.05)$. The two distributions are significantly different (Wilcoxon rank-sum test, $p<0.0001$ ). $d N / d S$ values higher than 10 were removed from the analysis (difference between species remained highly significant without the removal of outliers $p<0.0001$ ). Boxes encompass the lower and upper quartiles, with the internal line representing the median and whiskers extending to the $2.5^{\text {th }}$ and $97.5^{\text {th }}$ percentiles.

Figure 4. Proportion of sites predicted to be under positive selection. Proportion of sites predicted to be under positive selection for all proteins showing evidence of adaptive evolution under codon models M8 vs M8a $(p<0.05)$. The two distributions are significantly different (Wilcoxon rank-sum test, $p<0.0001$ ). Boxes encompass the lower and upper quartiles, with the internal line representing the median and whiskers extending to the $2.5^{\text {th }}$ and $97.5^{\text {th }}$ percentiles.

Figure 5. Comparison of $d N / d S$ values for all protein coding genes. $d N / d S$ values were estimated between the two most divergent lineages of Leishmania spp. ( $L$. braziliensis vs L. mexicana) or T. cruzi (T. cruzi Sylvio vs T. cruzi marinkellei), and $\mathrm{dN} / \mathrm{dS}$ values higher than 3 were removed from the analyses. The two distributions are significantly different between taxa $\left(p=3.25 \times 10^{-62}\right)$. If outliers with $d N / d S>3$ are not removed the difference between species remains highly significant $(p<0.0001)$. Boxes encompass the lower and upper quartiles, with the internal line representing the median and whiskers extending to the $2.5^{\text {th }}$ and $97.5^{\text {th }}$ percentiles.

Figure 6. Difference between $\mathrm{dN} / \mathrm{dS}$ values of housekeeping and hypothetical genes in $T$. cruzi spp. and Leishmania spp. dN/dS values were extracted from the output files of model M8 (see methods) and represent the average $\mathrm{dN} / \mathrm{dS}$ of the estimated parameter from every branch of the tree. ${ }^{* * *}$ Significant difference between the average $\mathrm{dN} / \mathrm{dS}$ values of housekeeping genes and hypothetical genes in $T$. cruzi spp. $\left(p=3.07 \times 10^{-25}\right)$ or Leishmania spp $\left(p=8.5 \times 10^{-15}\right)$. 
Table 1. Differences in the number of proteins under positive selection between the two lineages. T. cruzi taxa set consists of Non-Esmeraldo and Esmeraldo haplotypes, Sylvio, Jrcl4 strains (all T. cruzi cruzi strains) and T. cruzi marinkellei. The Leishmania spp. taxa set consists of L. braziliensis, L. mexicana, L. major and L. infantum. The conserved section represents the number of proteins with no evidence of positive selection by the LRT of model M7 vs M8 and M8 vs M8a in PAML with $p<0.01$ and $p<0.05$. ${ }^{*}$ False discovery rate corrected q-values.

\begin{tabular}{|c|c|c|c|c|}
\hline Taxonomic group & \multicolumn{2}{|c|}{ T. cruzi } & \multicolumn{2}{|c|}{ Leishmania spp. } \\
\hline Evolutionary pressure & Conserved (\%) & $\begin{array}{c}\text { Positive selection } \\
\text { (\%) }\end{array}$ & Conserved $\quad(\%)$ & Positive selection (\%) \\
\hline M7 vs M8 $(p<0.01)$ & $\begin{array}{c}3442(88.41 \%) \\
* 3680(94.52 \%)\end{array}$ & $\begin{array}{l}451(11.59 \%) \\
* 213(5.48 \%)\end{array}$ & $\begin{array}{c}7269(97.7 \%) \\
* 7430(99.8 \%)\end{array}$ & $\begin{array}{l}170(2.3 \%) \\
* 9(0.12 \%)\end{array}$ \\
\hline M7 vs M8 $(p<0.05)$ & $\begin{array}{c}3117(80.06 \%) \\
* 3505(90.03 \%)\end{array}$ & $\begin{array}{l}776(19.94 \%) \\
\star 388(9.97 \%)\end{array}$ & $\begin{array}{c}7030(94.5 \%) \\
* 7418(99.7 \%)\end{array}$ & $\begin{array}{c}409(5.5 \%) \\
* 21(0.28 \%)\end{array}$ \\
\hline M8 vs M8a $(p<0.01)$ & $\begin{array}{c}3491(89.67 \%) \\
* 3716(95.45 \%)\end{array}$ & $\begin{array}{l}402(10.33 \%) \\
* 177(4.55 \%)\end{array}$ & $\begin{array}{c}7361(99 \%) \\
* 7431(99.89 \%)\end{array}$ & $\begin{array}{c}78(1.04 \%) \\
{ }^{*} 8(0.1 \%)\end{array}$ \\
\hline M8 vs M8a $(p<0.05)$ & $\begin{array}{l}3179(81.65 \%) \\
* 3558(91.4 \%)\end{array}$ & $\begin{array}{l}714(18.34 \%) \\
* 335(8.6 \%)\end{array}$ & $\begin{array}{c}7218(97.02 \%) \\
* 7427(99.84 \%)\end{array}$ & $\begin{array}{l}221(2.97 \%) \\
* 12(0.16 \%)\end{array}$ \\
\hline
\end{tabular}


Table 2. Functional overrepresentation of genes showing evidence of positive selection.

\begin{tabular}{|c|c|c|c|c|}
\hline \multicolumn{5}{|c|}{ Trypanosoma cruzi } \\
\hline $\begin{array}{l}\text { Predicted } \\
\text { function }\end{array}$ & $\mathrm{N}$ & $\mathrm{n}$ & $p$ & Gene names \\
\hline Hypothetical & 2792 & 585 & 0.0072 & See Supp. Mat. \\
\hline $\begin{array}{l}\text { Mucin } \\
\text { associated } \\
\text { surface protein } \\
\text { (MASP) }\end{array}$ & 3 & 3 & 0.0079 & $\begin{array}{l}\text { Tc00.1047053511839.20, } \\
\text { Tc00.1047053506815.20, } \\
\text { Tc00.1047053507071.180 }\end{array}$ \\
\hline \multicolumn{5}{|c|}{ Leishmania spp. } \\
\hline $\begin{array}{l}\text { Predicted } \\
\text { function }\end{array}$ & $\mathrm{N}$ & $\mathrm{n}$ & $p$ & Gene names \\
\hline $\begin{array}{l}\text { Glutathione } \\
\text { peroxidase \& } \\
\text { synthetase }\end{array}$ & 2 & 2 & 0.00043037 & $\begin{array}{l}\text { LmjF.36.3010, } \\
\text { LmjF.14.0910 }\end{array}$ \\
\hline $\begin{array}{l}\text { ATP-binding } \\
\text { cassette protein } \\
\text { subfamily A, D } \\
\& G\end{array}$ & 34 & 5 & 0.00062779 & $\begin{array}{l}\text { LmjF.11.1270, } \\
\text { LmjF.11.1290, } \\
\text { LmjF.27.0970, } \\
\text { LmjF.33.1860, } \\
\text { LmjF.06.0090 }\end{array}$ \\
\hline $\begin{array}{l}\text { Iron superoxide } \\
\text { dismutase }\end{array}$ & 5 & 2 & 0.0041293 & $\begin{array}{l}\text { LmjF.32.1820, } \\
\text { LmjF.32.1830 }\end{array}$ \\
\hline $\begin{array}{l}\text { Cysteine } \\
\text { peptidase }\end{array}$ & 7 & 2 & 0.0084367 & $\begin{array}{l}\text { LmjF.29.0820, } \\
\text { LmjF.19.1420 }\end{array}$ \\
\hline
\end{tabular}

Note: N: number of proteins of this function in ortholog data set. $n$ : number of proteins of this function under positive selection under model M8 vs M8a. p: statistical significance estimated from GeneMerge. Gene codes are the gene codes for Non-Esmeraldo ( $T$. cruzi) and Leishmania major found in Tritrypdb.org. 
Table 3. Statistically overrepresented hypothetical protein clusters under positive selection in T. cruzi and Leishmania spp.

\begin{tabular}{|c|c|c|c|c|c|c|c|c|c|c|}
\hline $\begin{array}{l}\text { Protein } \\
\text { cluster }\end{array}$ & Contributing proteins & $\begin{array}{l}\text { Population } \\
\text { fraction }\end{array}$ & $\begin{array}{l}\text { Study } \\
\text { fraction }\end{array}$ & $p$-value & $\begin{array}{l}\text { p-value } \\
(\mathrm{BF})^{*}\end{array}$ & $\mathrm{dN} / \mathrm{dS}$ & $\begin{array}{l}\% \text { sites } \\
d N / d S>1\end{array}$ & $\begin{array}{l}\text { Ov. } \\
\text { expr }\end{array}$ & Syntenic & $\begin{array}{c}\% \text { identity } \\
\text { within cluster }\end{array}$ \\
\hline T.c.1 & $\begin{array}{l}\text { Tc00.1047053506559.20 } \\
\text { Tc00.1047053509039.10 }\end{array}$ & $2 / 7079$ & $2 / 479$ & 0.0045696 & 0.39299 & $\begin{array}{l}25.44 \\
12.64\end{array}$ & $\begin{array}{l}0.014 \\
0.034\end{array}$ & $\begin{array}{l}\mathrm{Am}, \\
\text { Epi }\end{array}$ & $\begin{array}{l}\text { Chr34, } \\
\text { Chr32 }\end{array}$ & $27 \%$ identity \\
\hline T.c. 2 & $\begin{array}{l}\text { Tc00.1047053507031.130 } \\
\text { Tc00.1047053509569.140 }\end{array}$ & $3 / 7079$ & $2 / 479$ & 0.013093 & 1 & $\begin{array}{c}6.12 \\
10.10\end{array}$ & $\begin{array}{l}0.063 \\
0.092\end{array}$ & $\begin{array}{l}\text { NA, } \\
\text { NA }\end{array}$ & $\begin{array}{l}\text { Chr40, } \\
\text { Chr12 }\end{array}$ & $39.25 \%$ \\
\hline T.C. 3 & $\begin{array}{c}\text { Tc00.1047053505999.170 } \\
\text { Tc00.1047053508299.30 } \\
\text { Tc00.1047053511287.4 }\end{array}$ & $9 / 7079$ & $3 / 479$ & 0.019016 & 1 & $\begin{array}{l}30.08 \\
24.15 \\
21.38\end{array}$ & $\begin{array}{l}0.005 \\
0.116 \\
0.023\end{array}$ & $\begin{array}{l}\text { NA, } \\
\text { NA, } \\
\text { NA }\end{array}$ & $\begin{array}{l}\text { Chr9, } \\
\text { Chr38, } \\
\text { Chr40 }\end{array}$ & $48.25 \%$ \\
\hline $\begin{array}{l}\text { L. spp. } \\
1\end{array}$ & $\begin{array}{l}\text { LmjF.09.1020 } \\
\text { LmjF.32.0510 }\end{array}$ & $3 / 6031$ & $2 / 102$ & 0.000840 & 0.08404 & $\begin{array}{l}10.849 \\
5.9108\end{array}$ & $\begin{array}{l}0.00557 \\
0.03476\end{array}$ & & $\begin{array}{l}\text { Chr 9, } \\
\text { Chr32 }\end{array}$ & $33 \%$ \\
\hline $\begin{array}{l}\text { L. spp. } \\
2\end{array}$ & $\begin{array}{l}\text { LmjF.29.1500 } \\
\text { LmjF.11.0670 }\end{array}$ & $17 / 6031$ & $2 / 102$ & 0.032657 & 1 & $\begin{array}{l}6.3739 \\
392.16\end{array}$ & $\begin{array}{l}0.01263 \\
0.00450\end{array}$ & & $\begin{array}{l}\text { Chr29, } \\
\text { Chr11 }\end{array}$ & $32.25 \%$ \\
\hline
\end{tabular}

Note: dN/dS: Average dN/dS for sites with dN/dS $>1$ from Model8 in PAML. \%sites dN/dS $>1$ : estimated from the M8 model implemented in PAML. Ov. Expr. NA: Data Non available. Am: Over-expressed in amastigote stage. Epi: over expressed in epimastigote stage. ${ }^{*}$ Bonferroni corrected p-values. 


\section{A Leishmania braziliensis $\mathbf{B}$}

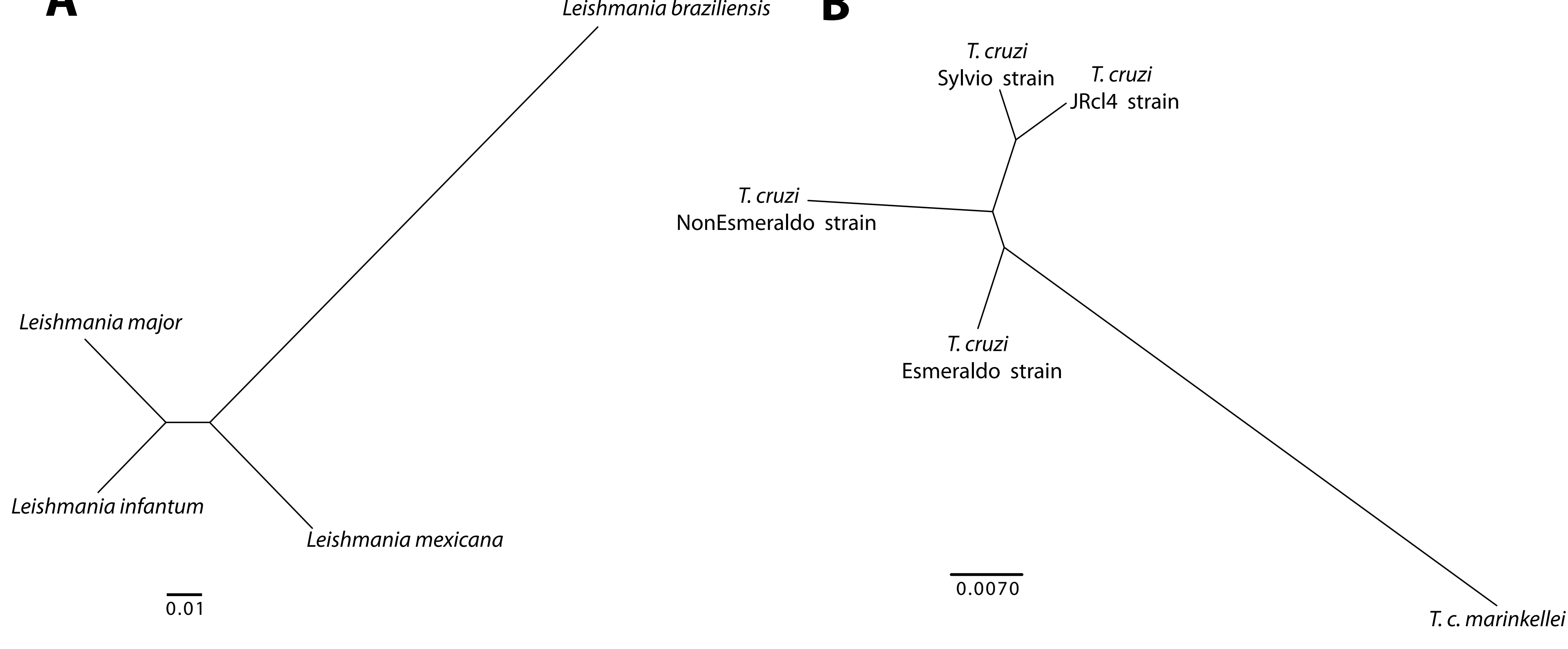




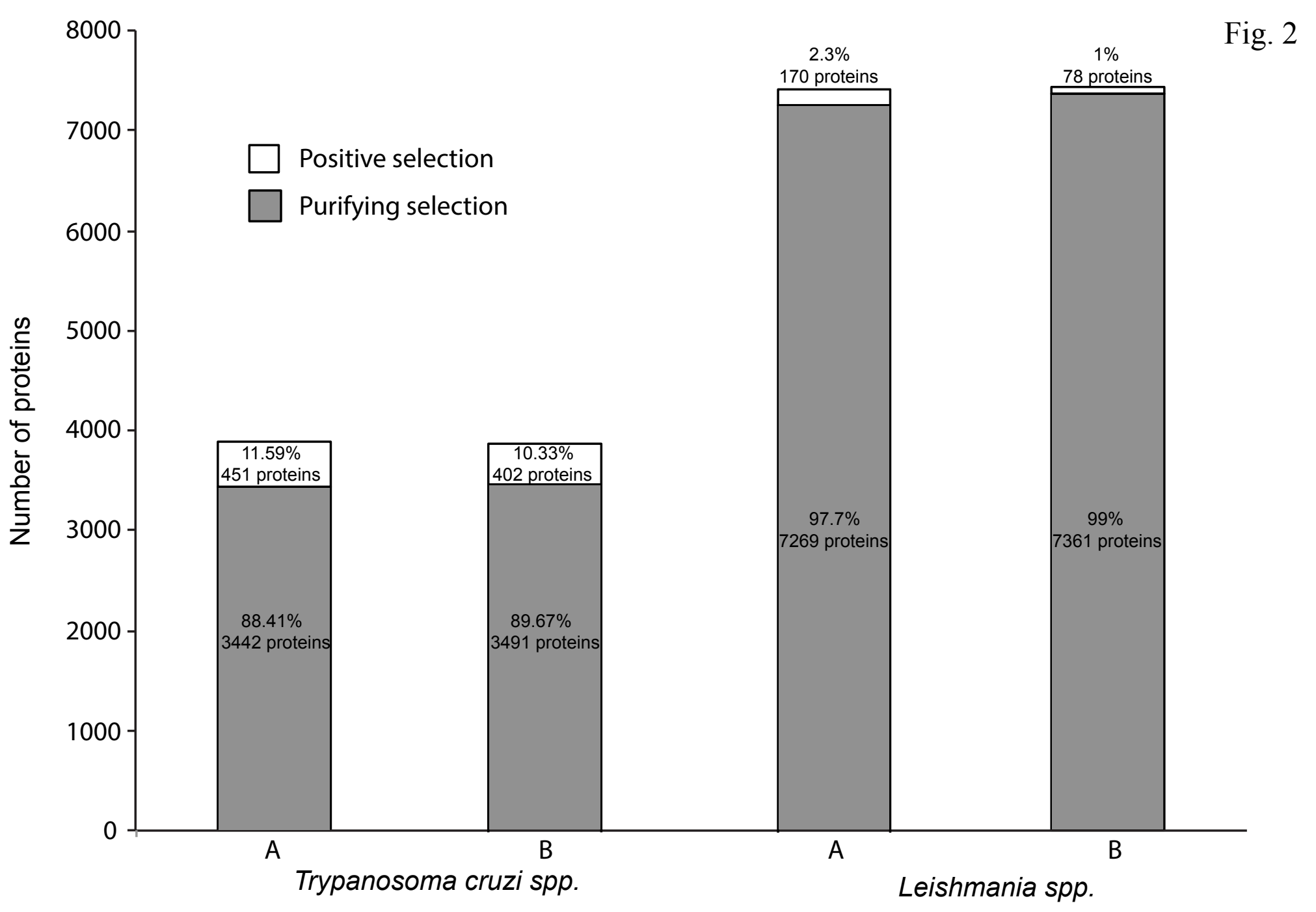


Fig. 3

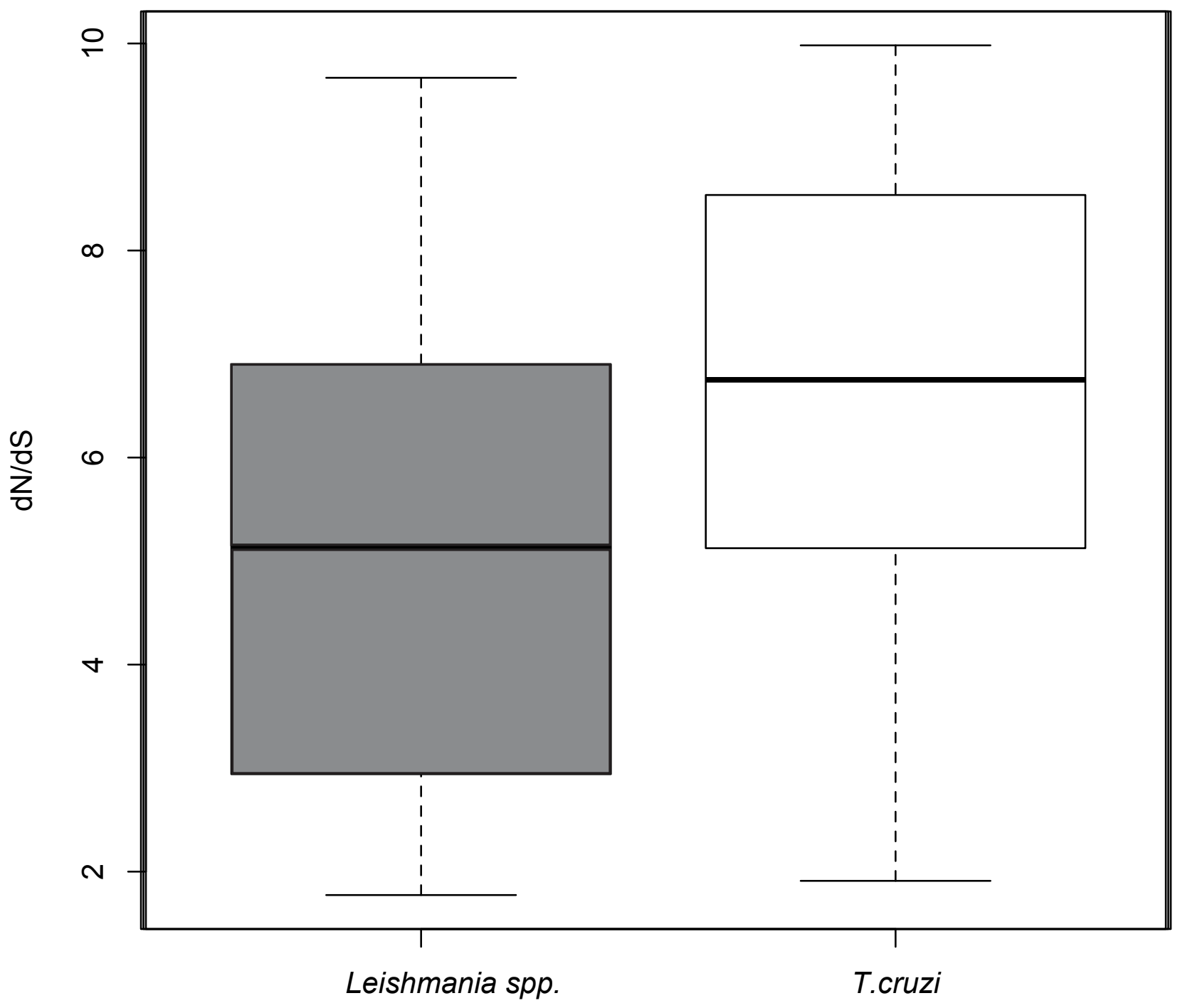


Fig. 4

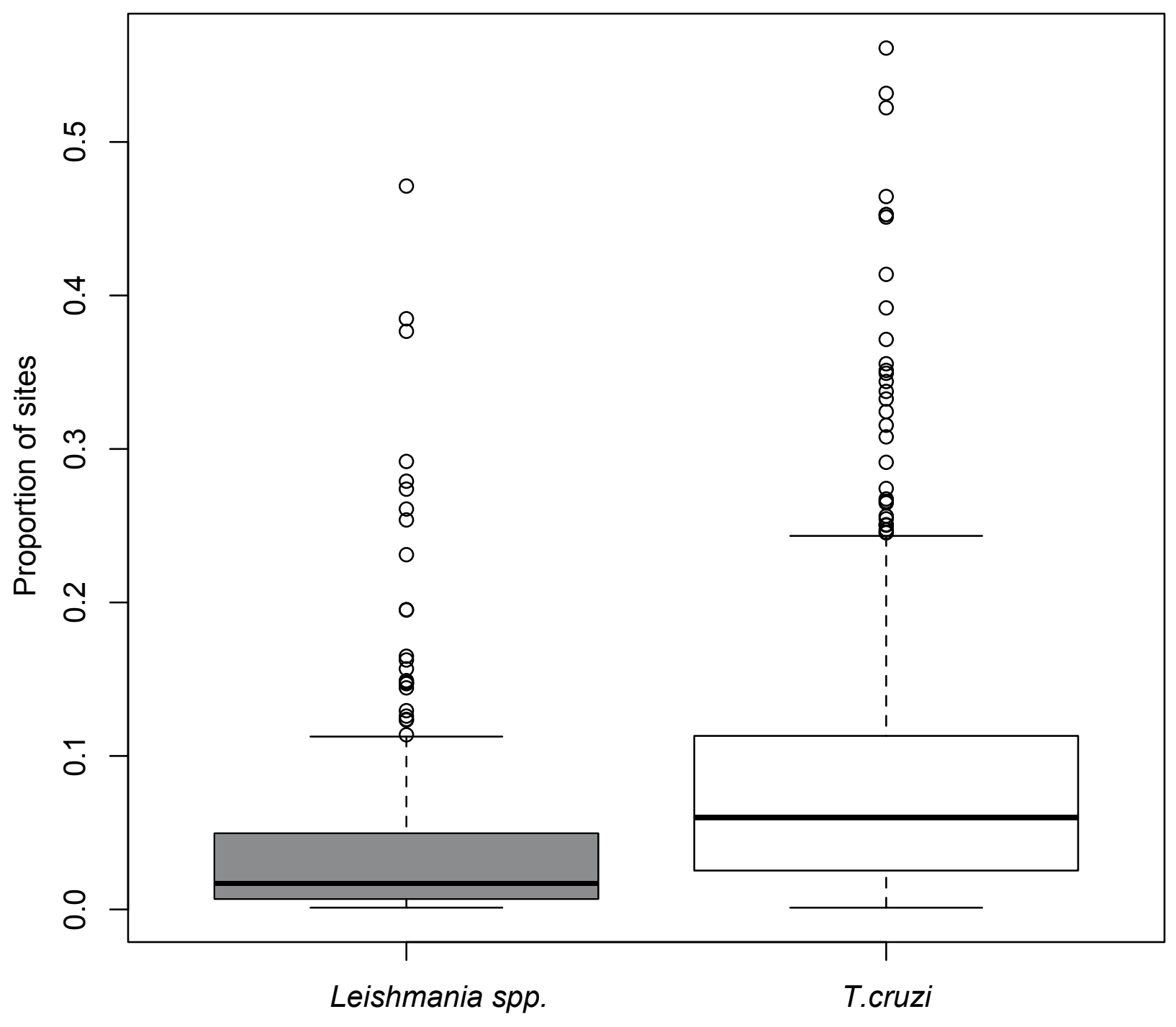


Fig. 5

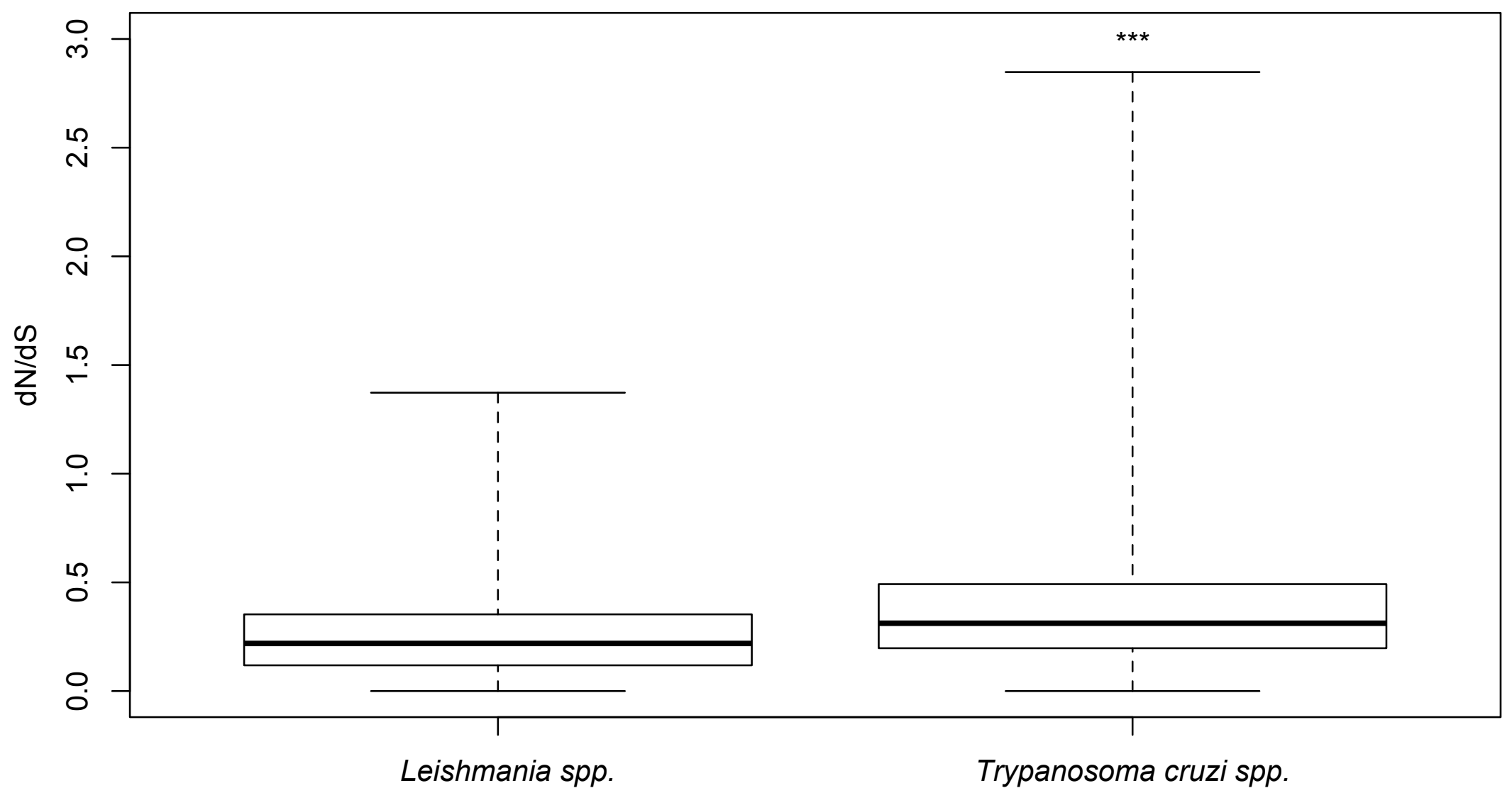


Fig. 6

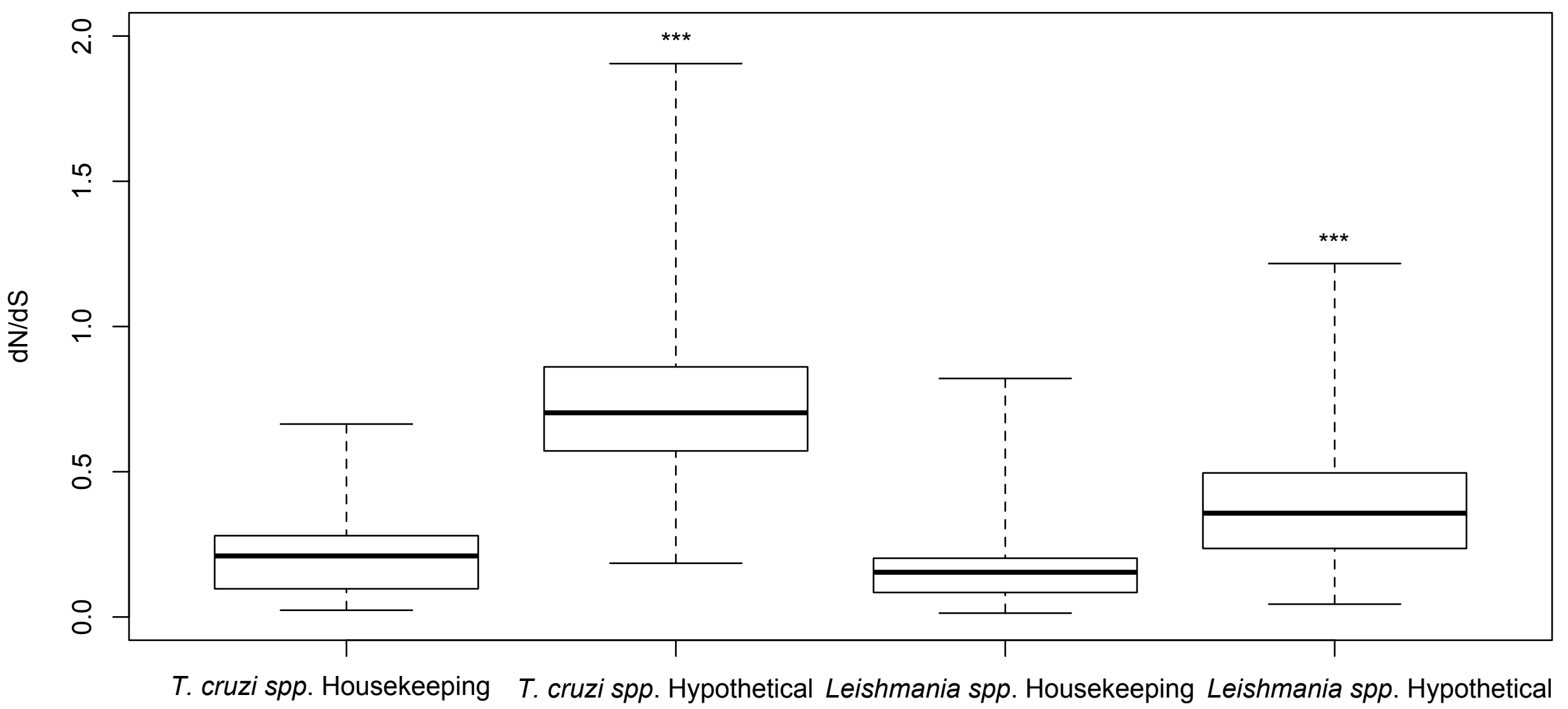

